\title{
TOWARD A BETTER UNDERSTANDING OF THE EVER EXPANDING SOCIAL WEB: A USES AND GRATIFCATION APPROACH
}

Anita Whiting, Clayton State University, USA

David Williams, Kennesaw State University, USA

\begin{abstract}
Social media (sometimes referred to as consumer generated media or interactive media) has developed into an area of immense interest for marketing scholars and practioners. Many organizations are using social media as part of their integrated marketing communication programs. Communicating with consumers via social media is thought to be very important especially within the coming years. Despite the importance and increased usage of social media, research on social media usage is lacking when compared to the more traditional components of the marketing mix. Therefore, this paper seeks to investigate why and how consumers use social media.

The current research explores why consumers use social media by applying usage and gratifications theory. In particular, this paper explores and identifies what uses and gratifications consumers identify as being important to them as they participate in social media networks. In-depth interviews are conducted with twenty-five consumers about their social media usage. Analyses of qualitative comments identify fifteen usages and gratification themes for social media usage. The fifteen usage and gratification themes combined with comments from consumers provide a rich and vivid understanding of why and how consumers use social media.
\end{abstract}

References available upon request 